\title{
Mercado imobiliário de bens patrimoniais: um modelo interpretativo a partir do centro histórico do Recife (Brasil) ${ }^{1}$
}

Norma Lacerda. Universidade Federal de Pernambuco, Recife, Brasil.

RESUmo | A partir do decênio de 1990, quando o Brasil se insere no processo de globalização da economia, os centros históricos das suas cidades -que, nas duas décadas anteriores, haviam sido abandonados pelas atividades de prestígio dos setores do comércio e dos serviços- passam a assistir à volta de investimentos nessas atividades, em partes dos seus territórios. Decerto, tais investimentos vêm tendo implicaçóes no desempenho dos respectivos mercados imobiliários. Daí o objetivo deste ensaio: desenhar -tendo como fundamento as características inerentes a esses mercados e a evidente dependência do seu dinamismo às políticas públicas- um esboço interpretativo do seu funcionamento, investigando-se os condicionantes da oferta e demanda, decorrentes dessas políticas, e as implicaçóes dos ajustes nos preços neles praticados.

PALAVRAS-CHAVE | mercado imobiliário, patrimônio, política urbana.

ABSTRACT | From the 1990s, when Brazil was engaged on the process of globalizing her economy, the historic centers of her cities -which, in the previous two decades, had been abandoned by the prestige activities of the commerce and service sectors-started to witness investments being put back into these activities, in parts of her territories. Of course, there have been implications as a result of such investments for the performance of the respective real estate markets. Hence the purpose of this study is: to sketch out-based upon the characteristics inherent in these markets and the obvious dependence of its dynamism on public policies- an interpretative outline of how this has been working, by investigating what factors condition supply and demand, arising from these policies, and the implications of the adjustments in prices carried out in these markets.

KEYWORDS | real estate market, heritage, urban policy.

1 Este artigo decorre da pesquisa Mercado Imobiliário nos Centros Históricos Brasileiros: Seus Submercados e Respectivas Dinâmicas Frente à Emergência de Novas Fronteiras de Valorização do Capital Imobiliário. 


\section{Introduçáo}

$\mathrm{Na}$ década de 1990, o cenário econômico brasileiro -marcado pela largada do processo de inserção do país na economia globalizada e pelos baixos índices nacionais de crescimento, aliados ao processo de descentralização político-administrativainstigou diversos governos locais a aderirem ao chamado modelo de planejamento estratégico de cidades (city marketing), visando à atração de empresas. É nesse contexto que os centros históricos, embora abandonados, passaram a ser reconhecidos por essas instâncias governamentais, como capazes de contribuir para o desenvolvimento local, e se tornaram objeto de fortes investimentos públicos e privados.

Não surpreende que tais investimentos tenham repercutido no funcionamento do mercado imobiliário desses centros, tema ainda pouco investigado nos meios acadêmicos brasileiros. Os estudos sobre o mercado imobiliário têm privilegiado os investimentos na produção de unidades habitacionais novas e suas implicaçóes na estruturação do espaço urbano. Por isso, estiveram fortemente relacionados às políticas nacionais de habitação. Não sem razão, adquiriram grande centralidade, durante a vigência do Banco Nacional de Habitação (BNH) (1964-1986), que assegurava recursos para a produção e a comercialização de imóveis residenciais. Perderam vigor entre a década de 1990 e a primeira metade dos anos 2000, em razão da ausência de uma política nacional nos moldes e dimensóes do BNH. Foram retomados recentemente, sob o impulso da vigência de uma nova política nacional de habitação. ${ }^{2}$

Quanto ao mercado imobiliário em centros históricos, só há bem pouco tempo vem sendo objeto de estudos. Destaque-se o pioneirismo da pesquisa em rede - coordenada pela autora deste texto e iniciada em 2013-, objetivando desvendar funcionamento desse mercado e tomando por objeto empírico de análise os centros históricos do Recife, Olinda, São Luís e Belém. No caso do Centro Histórico do Recife (CHR) -balizador das reflexôes aqui apresentadas-, a análise apontou que é composto de vários submercados, identificáveis pelos diversos níveis de qualidade das edificaçóes e do espaço público, assim como pelas funcionalidades e dinâmicas próprias, embora fortemente correlacionadas.

A partir daí surgiram os seguintes questionamentos: (i) quais elementos distinguem o mercado imobiliário em centros históricos no confronto com o mercado imobiliário de unidades novas? quais os condicionantes da oferta e da demanda por imóveis nos centros históricos? Essas indagaçôes evidenciaram a necessidade da

2 No período do $\mathbf{B N H}$, o financiamento de habitaçóes era essencialmente nacional, oriundo sobretudo do Fundo de Garantia por Tempo de Serviço (fgts) e da Sociedade Brasileira de Poupança e Empréstimo (sBPE). Na década de 1990 (governo Fernando Henrique Cardoso) surgiu um novo desenho do sistema de financiamento imobiliário, baseado em garantias hipotecárias. "Essa aproximaçấo entre mercado financeiro e a política habitacional se potencializou, a partir de 2005 [governo Luís Inácio da Silva], quando as empresas construtoras e incorporadoras abriram seu capital na Bolsa de Valores. Dessa forma, além dos fundos públicos, estava em jogo o capital financeiro internacionalizado, personificado nos investidores estrangeiros, que passaram a ser acionistas dessas empresas" (Shimbo, 2009). 
formulação de um referencial teórico, propiciador de elementos indispensáveis à análise das informaçóes levantadas.

Frente a essa exigência, é o seguinte o objetivo deste ensaio: desenhar um esboço interpretativo do funcionamento do mercado imobiliário, em centros históricos brasileiros, investigando-se os condicionantes da oferta e demanda, decorrentes das políticas públicas, adotadas a partir dos anos de 1990, e as implicaçóes desses condicionantes nos preços neles praticados.

Realizar esse objetivo demanda, em primeiro lugar, caracterizar-se o mercado imobiliário nos centros históricos, no que diz respeito aos tipos de bens transacionados, aos agentes imobiliários que operam nele, destacando seus respectivos níveis de informação, e às suas particularidades, notadamente no confronto com o mercado imobiliário de unidades habitacionais novas. Em seguida, mostrar-se -tomando por balizamento o Centro Histórico do Recife- que os investimentos privados nos centros históricos são tributários de políticas públicas capazes de promover ajustamentos entre a oferta e a demanda por espaço construído e, como desdobramento, proporcionar um novo dinamismo imobiliário (valorização), em certas porçóes dos seus respectivos territórios. Esses dois momentos -o de caracterização dos bens transacionados e dos agentes desse mercado, e o de análise da dependência do retorno desses investimentos às políticas públicas- fornecerão os elementos essenciais para (i) o reconhecimento do modelo de mercado, a partir do qual tais agentes tomam suas decisóes, e (ii) o desenho do esboço interpretativo do funcionamento do mercado em questão, considerando-se os últimos 25 anos.

\section{Particularidades do mercado imobiliário em centros históricos}

Para apreender os mecanismos presentes no funcionamento de qualquer mercado, é necessário, de início, caracterizar os tipos de bens transacionados e os agentes que operam neles. No caso do mercado imobiliário nos centros históricos, os produtos são materialmente diversos, quanto a tipo (sobrado, casa, apartamento, sala, loja, garagem), tamanho, material de construção, estado de conservação e, por óbvio, localização dos imóveis. Nesse mercado, comercializam-se imóveis com poucos metros quadrados (como salas, isto é, com tamanho suficiente para a instalação de um pequeno comércio ou serviço), mas também com muitos metros quadrados (capazes de abrigar uma loja de departamento, por exemplo). São também negociados, tanto imóveis em ruína, quanto outros em excelente nível de conservação. Transacionam-se espaços para diferentes fins comerciais e de prestação de serviço, bem como para fins habitacionais. São comprados imóveis novos (poucos) e imóveis seculares. Sem dúvida, trata-se de um mercado de produtos fortemente heterogêneos, bem distinto do mercado de imóveis habitacionais novos, onde, evidentemente, existem diferenciaçôes, embora não tão acentuadas, dado não se tratar de bens de tão diferentes épocas.

Nos centros históricos, os preços se descolam dos preços originais de produção dos imóveis à venda. Como se sabe, o preço de produçáo de um imóvel novo é formado pelos custos de produção, acrescidos do lucro médio praticado pelo setor imobiliário. Ora, como diz respeito a bens edificados em períodos diversos, o preço 
de produção encontra-se diluído durante a sua longa vida. Se o preço de mercado não mantém relação com o preço de produção, é mais apropriado falar-se em preço, essencialmente dependente das condiçóes de circulação que, no caso em pauta, são subordinadas ao poder de compra de uma demanda, interessada por localizaçóes não reproduzíveis.

Todavia, as diferenciações não são unicamente relativas aos produtos imobiliários disponibilizados no mercado, mas também concernem às diferenciaçóes espaciais, isto é, às diversas localizaçóes existentes em um dado centro histórico. Essas diferenciaçóes revelam-se na qualidade dos espaços públicos, na oferta de infraestruturas e serviços e, também, no grau de concentração de determinadas atividades. Afinal, é a concentração de compradores de determinados produtos (em certas áreas, ruas ou entroncamentos) e a raridade de estabelecimentos disponíveis (para serem transacionados) que conferem, a cada modalidade de produto e de serviços (eletrodomésticos, serviços de tecnologia da informação e comunicação, serviços educacionais...), um preço, decorrente da localização. Náo surpreende, pois, que, em cada um dos centros analisados, no âmbito da mencionada pesquisa, tenham sido encontradas concentraçóes espaciais de determinados estabelecimentos.

Quanto aos agentes, a pesquisa em andamento identificou os mais importantes. Além dos vendedores e compradores, locadores e inquilinos, atuam as três esferas de governo: federal, estadual e municipal. A interferência dessas esferas ocorre, notadamente, por meio de políticas públicas de dotação e/ou renovação de infraestruturas, disponibilidade de crédito, renúncia fiscal, cessão de espaços construídos e terrenos, tornando-se agentes decisivos, para viabilizar o retorno do capital aos centros históricos (questão a ser abordada mais adiante, com o exemplo do cHR).

No que respeita aos vendedores e locadores, algumas características foram identificadas. Eles atuam, a partir de estratégias ora convergentes (quando se considera seu comportamento no interior do centro histórico), ora divergentes (vis à vis ao comportamento dos agentes que atuam no mercado imobiliário de unidades habitacionais novas). Tais comportamentos apresentam variaçóes, conforme o período considerado, e revelam a lógica de valorização -ou desvalorização- de seus respectivos capitais imobiliários.

Estratégias convergentes ocorrem, porque, no caso dos referidos centros, a maioria dos proprietários de imóveis foi submetida -como anotado- a um processo de desvalorização dos seu(s) imóvel(eis). Ora, a desvalorização, conforme Neil Smith (2003), faz parte da lógica de funcionamento do mercado imobiliário em geral, que provoca a degradação desses centros e, como desdobramento, a diminuição dos preços de venda dos imóveis (rent gap) e dos aluguéis, afetando negativamente os vendedores e os locadores que atuam neles e beneficiam os capitalistas atraídos por essas áreas, em decorrência, como se verá adiante, das benesses ofertadas por meio das políticas públicas.

Já as estratégias divergentes acontecem, porque os proprietários se comportam de forma diferenciada dos agentes que conformam a oferta do mercado imobiliário de habitaçóes novas. Sabe-se que, no caso brasileiro, a Política Nacional de Habitação, capitaneada pelo BNH, foi responsável por um processo, até então sem precedente, de acumulação de capital, no âmbito do setor imobiliário. Tal processo teve, 
entre outras consequências, a substituição de antigas estruturas residenciais de alta qualidade por estruturas verticalizadas e a criação de novas centralidades (Lacerda, Zancheti \& Diniz, 2000). Foi e continua significando uma destruiçấo criativa, para utilizar os termos do economista austríaco Joseph Schumpeter (1883-1950), reconhecido como profeta desse tipo de destruição, por ele considerada como fator essencial da realidade capitalista. No caso do setor imobiliário, tal fator escancara a imprescindibilidade da constante procura de inovaçóes espaciais, à custa, muitas vezes, do aniquilamento de espacialidades pré-existentes.

Foi exatamente nesse contexto que os centros históricos foram fortemente penalizados. As normas protecionistas, aliada a ausência de incentivos, poupavam-nos da destruição criativa, ao custo de baixos preços imobiliários, que passaram a significar a condição necessária para -em futuro não tão longínquo- o retorno do interesse do capital por essas áreas, como bem admite Smith (2003). Neste caso, trata-se de capital referido às tradicionais empresas do mercado imobiliário, mas também a empresas do moderno setor comercial e de serviços.

Embora Smith (2003) anuncie o retorno do interesse do capital pelos centros históricos, não esclarece quais os tipos de capital em jogo nesse processo, os seus detentores e suas respectivas estratégias. Dito de outra maneira, ele não explicita que, em geral, se trata de dois grupos de agentes rivalizando-se.

De um lado, estáo os proprietários de bens imobiliários que -localizados nos centros históricos, quase sempre antigos, e destinados a abrigar vários tipos de atividade- são regidos por normas urbanísticas restritivas do direito de intervenção e adaptação. Os instrumentos legais de preservação levam a supor-se que a vida útil do imóvel não se esgotará, "tendo em vista a obrigatoriedade da sua preservação, aliada ao fato de não ser permitido acréscimo na ocupação dos seus terrenos. Adicione-se, ainda, que nesse centro é vetada a utilização do remanescente do terreno para a construçáo de edifício verticalizado, pois este prejudicaria a integridade da paisagem histórica da área de ambiência” (Bernardino \& Lacerda, 2015). Sendo assim, existem duas opçóes para esses proprietários: ruína ou reforma. Trata-se, portanto, de um mercado com alto grau de inelasticidade por parte da oferta. É esse mercado que, a partir da década de 1990, será reinventado. Novas combinaçôes -nos termos mais adiante explicados- serão neles introduzidas.

Do outro lado, estão os produtores de bens imobiliários novos que -localizados fora das áreas históricas e direcionados, na sua grande maioria, ao atendimento dos anseios de uma demanda habitacional, formada por indivíduos de média e alta renda- são regidos por normas urbanísticas de relativamente alto nível de flexibilidade. Está-se, pois, diante de um mercado de elevado grau de elasticidade da oferta e, além disso, "pautado na 'negação', na 'desconstrução' do centro histórico enquanto lugar de moradia” (Bernardino \& Lacerda, 2015, p. 62). Trata-se de um mercado estimulado por políticas habitacionais direcionadas à produção e à comercialização de novas unidades habitacionais e, com elas, a emergência de novas espacialidades.

O grau de elasticidade da oferta depende, em grande parte, da propensão dos empresários do setor imobiliário para empreender combinações náo habituais. Schumpeter, no seu livro Teoria do desenvolvimento econômico (2012) considera que o termo empreendimento deve ser utilizado unicamente quando se trata de 
novas combinaçóes. Convém reproduzir uma passagem do aludido compêndio: "Damos o nome de 'empreendimento' à implantação de novas combinaçóes, assim como também às suas materializaçôes em instalaçóes fabris etc. Chamamos empresários aos sujeitos econômicos cuja função é a imposição de novas combinaçóes, e que são o elemento ativo" (Schumpeter, 2012, p. 152). No caso do tradicional setor de produção de habitaçóes novas, os empresários são os promotores imobiliários, que lançam novas combinaçóes, cujas materializaçóes são inovaçóes, em termos de produto e/ou de espacialidade (condomínios fechados com variados serviços, bairros planejados...).

São novas combinaçôes, no sentido da utilização das possibilidades econômicas existentes, assumindo, conforme Schumpeter (2012), formas diferenciadas: (i) produção de um novo bem para uma clientela ainda não familiarizada; (ii) introdução de um novo método de produção, que o respectivo ramo industrial ainda náo conhece; (iii) abertura de uma zona de venda, ou seja, de um mercado no qual o respectivo ramo ainda náo tenha sido introduzido; (iv) conquista de uma nova fonte de fornecimento de matérias primas; e (v) introdução de uma reorganização, como a criação de monopólio. Em suas linhas centrais, a implantação de novas combinaçóes resulta em uma destruição criativa, termos tão caros para apreender-se a lógica dos promotores mobiliários, no que se refere à criaçáo de novos produtos e espacialidades, inculcando novas necessidades nos consumidores, ao custo da destruição de parte da cidade existente.

Importa esclarecer que, no caso dos centros históricos, o comportamento dos proprietários de imóveis, durante as décadas de 1970 e 1980, não foi guiado pelas referidas combinaçóes. Dito de outra maneira, esses proprietários não se comportavam como empresários schumpterianos. Muitos deles conservavam os imóveis precariamente. O poder público, por sua, vez, não mantinha de forma adequada as infraestruturas e os serviços urbanos existentes. Agindo desse modo, ele participava, juntamente com os proprietários, da reprodução das precárias espacialidades existentes. $\mathrm{Na}$ medida em que os bens imobiliários se degradavam, os vendedores ou locadores não conseguiam realizar as expectativas do mercado de imóveis do restante da cidade. É como se cada um deles estivesse seguro do chão onde pisava: sentia-se apoiado pela inércia dos demais que, por sua vez, esperavam dele o comportamento habitual. Abandonar esse comportamento seria enfrentar o novo e, com ele, a incerteza.

Isso ocorreu nesses centros, nas duas referidas décadas, por causa da ausência de políticas públicas, capazes de garantir meios necessários à circulação dos bens imobiliários, isto é, que assegurassem, entre outros incentivos, concessóes de créditos suscetíveis de afastar esses vendedores não schumpterianos, substituindo-os por empresas ou investidores individuais. Esses últimos seriam atraídos pelos prováveis ganhos, provenientes do aluguel às empresas que, por sua vez, deteriam as condições necessárias à modernização dos imóveis, graças a incentivos que lhes propiciassem a elevação do respectivo poder de compra.

Os ensinamentos de Schumpeter -embora não direcionados à análise do mercado imobiliário, mas ao exame do desenvolvimento econômico em geral- são valiosos, para entender o porquê desse retorno, ou seja, dos investimentos nos centros 
históricos das cidades brasileiras. Para esse economista, a imposição de novas combinaçóes -que, ao contrário das já existentes, não podem ser financiadas por rendimentos do percurso habitual do capital- exige dispor-se de crédito.

A conexão entre crédito e implantação do novo, que aqui já se anuncia e que será mais tarde expressa de forma muito mais nítida, não se pode também estranhar, porque, em primeiro lugar, é mental como historicamente óbvio que o crédito é necessário sobretudo para isso, e que desta maneira também se embrenhou nas atitudes de empresa 'correntes' - por um lado, porque era preciso para a sua fundação, por outro, porque o seu mecanismo, uma vez existente por razóes óbvias também se estendeu às antigas combinaçóes. [...] O sistema capitalista de crédito surgiu de facto do, e ligado ao financiamento de novas combinaçóes- em todos os países, ainda que em cada um deles de maneira específica. (Schumpeter, 2012, pp. 144-145)

Com o objetivo de melhor apreender a função do crédito e de outros tipos de incentivo, no processo de retorno do interesse do capital pelos centros históricos, mostrar-se-ão, a seguir, as políticas públicas, implantadas nos últimos 25 anos e rebatidas neles. A análise terá por fundamento o CHR.

\section{Incentivos financeiros setoriais: emergência de novas espacialidades no Centro Histórico do Recife}

A Cidade do Recife ${ }^{3}$ surgiu na primeira metade do século xvi. Teve como início um ancoradouro natural, formado por arrecifes, que servia de porto. Sua mais importante função era a exportação do açúcar produzido nos engenhos que ocupavam as várzeas dos rios Capibaribe e Beberibe. Em decorrência dessa atividade portuária, surgiu um povoado na Ilha do Recife, então conhecida como Povoação dos Arrecifes ou Ribeira Marinha dos Arrecifes, hoje Bairro do Recife. A partir do século XvII, a ocupação foi se estendendo, primeiramente para os bairros de Santo Antônio e São José e, posteriormente, para o Bairro da Boa Vista. São esses quatro bairros que a grosso modo conformam o CHR. ${ }^{4}$ No início do século $\mathrm{xx}$, em decorrência do seu estado de degradação, foi objeto de intervençôes urbanísticas. Todavia, no período de 1970 a 1990, conheceu outro processo de degradação.

A primeira iniciativa para reverter esse quadro decorreu do Plano de Revitalização do Bairro do Recife (PRBR) (1992), o qual fazia parte do Programa Integrado de Desenvolvimento do Turismo no Nordeste (Prodetur), gerenciado pelo Banco do Nordeste, com recursos do Banco Interamericano de Desenvolvimento

A Cidade do Recife, núcleo da Regiāo Metropolitano do Recife (RMR) abrigava, segundo dados do (IвGE) de 2010, 1.537.704 habitantes. A RMR, por sua vez, contabilizava 3.668.428 habitantes.

4 Não existe uma delimitação formal do CHr. Este artigo considera que ele é formado pelas Zonas Especiais de Preservação do Patrimônio Histórico-Cultural, definidas pela Lei de Uso e Ocupação do Solo (1996): ZepH 8 (parte do Bairro da Boa Vista e pequenos trechos dos Bairros de Soledade, Santo Amaro e Coelhos), chamada de Bairro da Boa Vista; ZePH 9 (Bairro do Recife); e zePH 10 (Bairro de Santo Antônio e parte do Bairro de São José). A partir dessas ZEPH, foram identificados os Setores Censitários (IBGE, 2010) correspondentes e definido o perímetro de análise, conforme figura 1. 
(BID) (Zancheti \& Lacerda, 1998). Tinha como objetivo transformar a economia do bairro, tornando-o um centro regional de serviços modernos, comércio, lazer e cultura, para a população da cidade, e um centro de atração turística nacional e internacional. O Plano foi conduzido mediante uma estratégia de parceria entre o poder público e agentes privados. Para atrair esses agentes, o poder público fez uma série de investimentos em recuperação das infraestruturas. Ademais, a implantação do Plano foi acompanhada por uma legislação que instituía renúncia fiscal do Imposto Predial e Territorial Urbano (IPTU) e do Imposto Sobre Serviços (ISs). O primeiro tipo de renúncia incidia sobre os imóveis recuperados, importando o não pagamento do IPTU, durante determinado período (de 2 a 10 anos), dependendo do tipo de trabalho realizado no imóvel (da simples reforma até a restauração). $\mathrm{O}$ segundo correspondia a uma renúncia de $5 \%$ sobre o faturamento total da atividade que viesse a se localizar no bairro em questão. Procurava-se re(criar) aquela espacialidade, a partir de uma nova combinação: edificaçôes antigas passariam a abrigar serviços modernos de comércio, de lazer e de cultura. E, para isso, era necessária, além da renúncia, a renovação das infraestruturas e a concessão de créditos para a recuperação das edificações, o que se deu por meio do Programa Monumenta. ${ }^{5}$

Apesar de todo o aparato ofertado às firmas pelo poder público, a partir do final da década de 1990, algumas atividades (como bares e restaurantes) fecharam suas portas, na medida em que não existia, no próprio bairro, demanda gerada por outras atividades. De qualquer forma, os empresários das mencionadas atividades miraram o novo, tentaram construir para eles um novo caminho e fracassaram. Contudo, o percurso de rentabilidade estava aberto para outros agentes, inclusive para os proprietários de imóveis desse bairro, os quais assistiram a uma valorizaçáo imobiliária, no período de 1993 a 1996 (Zancheti \& Lacerda, 1999), colocando-os em posição privilegiada para a realização de preços de monopólio.

Diante do que se vinha assistindo, não surpreende que, desde o início do presente século, as estratégias do Plano de Revitalização tenham sido abandonadas, começando-se um novo ciclo: o Governo do Estado de Pernambuco lançou o Projeto Porto Digital Empreendimentos e Ambiente Tecnológico (2000), resultado de uma tríplice operação concertada, envolvendo as esferas pública, privada e acadêmica, com foco no desenvolvimento de software. A área para a instalação desse parque tecnológico foi o Bairro do Recife. No sentido de prepará-lo para recepcionar as empresas, fizeram-se altos investimentos (aproximadamente 38 milhóes de dólares a preços de maio de 2017) ${ }^{6}$ pelo Governo do Estado de Pernambuco, resultando na implantação de $8 \mathrm{~km}$ de fibras óticas e $26 \mathrm{~km}$ de dutos de ventilação e saneamento (www.olhardigital.uol.com.br). Dessa forma, o Estado passou a ofertar segurança e rapidez nos fluxos de informação, elemento essencial nos critérios de decisão

O Programa Monumenta, direcionado a áreas históricas, é realizado por meio de empréstimos da Uniấo junto ao Banco Interamericano de Desenvolvimento (BID), com o objetivo de recuperar espaços públicos e edificações privadas.

6 Segundo Albuquerque (2016), desde a formação (2001) do contrato de gestáo entre o Governo do Estado e o Núcleo Gestor do Porto Digital (qualificado como uma Organização Social), até 2015, foram repassados pelo setor público estadual, a esse Núcleo, R\$ 64.180.694, destinados a açóes de tecnologia e aprimoramento das infraestruturas. 
locacional das empresas de TIC. A iniciativa contou, segundo Lacerda e Fernandes (2015), também com o apoio da Financiadora de Estudos e Projetos (FInep), por meio do primeiro edital de parques tecnológicos. ${ }^{7}$ Acresce, ainda, como incentivo, a Lei da Informática, editada em $1991 .^{8}$ Consoante as aludidas autoras,

O parque tecnológico compreende atualmente 255 'empresas embarcadas', além de um conjunto de instituiçôes dos setores de tic e da chamada Economia Criativa. Embarcadas são chamadas as empresas que, por se localizarem na ilha, gozam de incentivo fiscal municipal específico, a redução de $5 \%$ para $2 \%$ do Iss, sendo esse um fator não desprezível para a atratividade locacional do Bairro do Recife. Referindose às empresas, o NGPD [Núcleo Gestor do Porto Digital] calcula que empreguem cerca de 7.100 profissionais qualificados, 500 dos quais empreendedores, e que seu faturamento tenha ultrapassado a marca de um bilhão de reais nos últimos três anos, a partir de contratos de prestação de serviços firmados com clientes locais e de fora do Estado, sendo que estes últimos representariam 65\% do total. (Lacerda \& Fernandes, 2015, p. 238).

O incentivo fiscal, principal benefício disponibilizado às empresas "embarcadas", consiste na redução de 60\% do Iss, assegurada pela Lei no $17.244 / 2006$, alterada pela Lei $n^{\circ} 17.942$, de 2013, para ampliar a abrangência territorial do Parque, que passou a incluir um quadrilátero no Bairro de Santo Amaro. Em 2015, uma nova alteração (Lei no 18.168), incluiu os bairros de Santo Antônio, uma parte do de São José e os lotes da Avenida Conde da Boa Vista. Em suas linhas centrais, a ideia é conferir maior elasticidade na oferta de imóveis destinados ao desenvolvimento desse ambiente tecnológico. Tal expansão, como bem admitiu o presidente do ngpd ao Jornal do Commercio (2015), deve-se à falta de espaço no Bairro do Recife, com repercussóes nos seus preços imobiliários, que passaram a deter fortes componentes de monopólio locacional.

Os imóveis comerciais e de serviços valorizaram-se 132\%, no período de 2008 a 2013, tempo escolhido pela aludida pesquisa sobre os centros históricos ${ }^{9}$ (Lacerda $\&$ Anjos, 2014). Tal valorização, estimada a partir dos dados das transaçóes de compra e venda constantes do Cadastro do Imposto Predial e Territorial Urbano (IPTU),

7 Os projetos aprovados incluíram os parques de Belo Horizonte, Campinas e Florianópolis e Recife.

8 Esta Lei (no 8.248/1991) dispõe sobre a capacitação e competitividade do setor de informática e automação, institucionalizando a redução de até $95 \%$ do Imposto sobre Produto Industrializado (IPI), a depender do intervalo dos períodos estabelecidos-estendem-se até 2029- e da macrorregião geográfica brasileira.

9 A demarcação desse período deveu-se ao fato de, em 2008, a economia mundial ter mergulhado numa severa crise, ocasionada pelo setor imobiliário dos Estados Unidos, interrompendo o mais longo ciclo de crescimento econômico do Brasil, em período recente. A resposta do País para o enfrentamento dessa crise consistiu em expandir o gasto público, a partir de um conjunto de medidas, dentre as quais, a redução da taxa de juros dos financiamentos habitacionais e a flexibilização das regras de concessão desses financiamentos, providências importantes para a ampliação da procura por unidades residenciais. Como resultado, o mercado imobiliário -não apenas residencial- experimentou acelerada valorização dos preços. Essa realidade se manteve até 2013, quando o País entrou novamente em crise. 
mostra-se superior à média nacional $(121,6 \%)$ de venda do metro quadrado de unidades habitacionais novas (Nakagawa, 2014). Quanto à evolução desse mesmo preço, no Recife, dispóe-se apenas da informação relativa ao período de julho de 2010 a outubro de 2013: o Índice FIPE-ZAP, que sinaliza uma valorização de 84,5\% (muito aquém, portanto, dos $132 \%$ do Bairro do Recife, muito bem posicionado nacional e localmente). Cabe anotar que a evolução do Índice Geral de Preços -Mercado (IGPM), nesse mesmo período, foi de 42,80\% (http://calculoexato.com.br). Ademais, como apreendido durante a pesquisa, o prestígio - enquanto função de diferenciação para as empresas localizadas no Bairro do Recife- também contribui para essa valorização. A figura 1 indica a variação do preço médio por metro quadrado em cada bairro do cHr que, grosso modo, corresponde a um submercado imobiliário.

FIGURA I | Centro Histórico do Recife. Valorização da média dos preços dos imóveis comerciais e de serviços por submercado (bairros). ITBI, 2008-2013

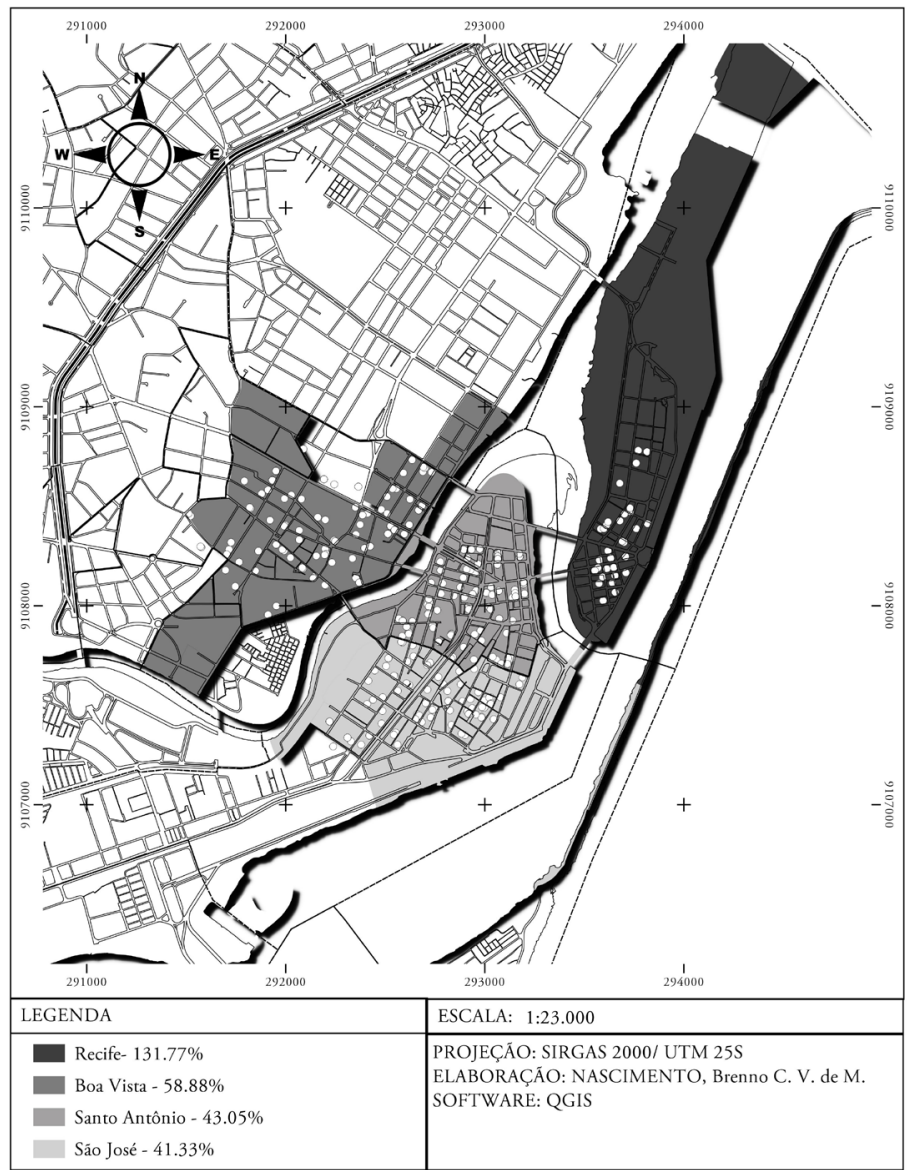


Acresce, como indicado por Lacerda e Fernandes (2015), a cessão, ao NGPD, por parte do Governo do Estado, de espaços construídos, alugados às empresas de TiC e de Economia Criativa. Esse Núcleo (uma organização privada sem fins lucrativos) vem atuando como agente imobiliário, ora viabilizando espaços físicos, mediante cessão onerosa ou não, ora identificando aqueles disponíveis no aludido mercado.

Some-se a isso a mais recente operação no Bairro do Recife: o Projeto Porto Novo, intervenção urbana no Cais do Porto, em implantação desde 2012. Este Projeto pretende -por meio da recuperação dos oito antigos armazéns e da dotação de infraestruturas do Porto- integrar lojas, bares e restaurantes, escritórios, cinemas, museu, centro de convençóes e terminal marítimo de passageiros. $\mathrm{O}$ megaempreendimento vem sendo viabilizado mediante parcerias público-privadas. O poder público cedeu a área (mediante arrendamento), por 25 anos, ao Consórcio Porto Novo Recife, formado pelo Grupo Excelsior, ${ }^{10}$ GL Empreendimentos, Hima Participaçóes sa e Maxxima Empreendimentos Imobiliários. Uma nova espacialidade, a partir de novas combinaçôes financeiras, vem sendo recriada ali.

As políticas públicas nacionais direcionadas à educação superior -em implantação por meio do Programa Universidade para Todos (ProUni, bolsas de estudo para alunos carentes, instituído em 2004), do Fundo de Financiamento Estudantil (Fies, criado em 1999, aumento da demanda por vagas nas universidades) e do Programa de Melhoria do Ensino das Instituiçóes de Educação Superior (IEs, criado 2009 e destinado a obras civis e equipamentos) - têm tido, também, implicaçóes no CHR, notadamente no Bairro de Santo Antônio. Este bairro, à conta da oferta de imóveis com preços relativamente baixos (rent gap), em decorrência dos respectivos estados de conservação e do fato de estarem situados no coração da metrópole recifense, foi descoberto pelo setor privado de educação superior. Nele, a quantidade de transaçôes de compra e venda, no período de 2008-2013, foi significativa (482), frente ao respectivo estoque de endereços (1.470), valendo ressaltar-se que a quase totalidade negociada se destinou a estabelecimentos de ensino superior. O relativamente baixo preço praticado no período -quando a valorizaçáo dos imóveis comerciais e de serviços chegou a apenas 43,5\% (Lacerda \& Anjos, 2014) ${ }^{11}$ - revela o grau de deterioração das edificaçốes e, ao mesmo tempo, a disposição de as empresas arcarem com os custos de recuperação, apostando na criação de um ambiente de geração de conhecimento. Com a recente expansão territorial do favorecimento fiscal às empresas de TIC e de Economia Criativa aos demais bairros do CHR, essas firmas ficam, obviamente, mais bem posicionadas no mercado imobiliário de compra e venda e de aluguel. Com a isenção de $60 \%$ do Iss, poderão arcar com maiores custos de acesso ao espaço construído neste bairro.

10 O Grupo Excelsior atua internacionalmente, inclusive no ramo financeiro. A matriz da Companhia Excelsior de Seguros foi transferida do Rio de Janeiro para o Recife, em 1996. Passou a ocupar um prédio no Bairro do Recife. A gL empreendimentos, atuante na cidade de Belo Horizonte, é também uma das empresas integrantes do megaempreendimento Novo Recife, situado no Cais José Estelita. A Maxxima Empreendimentos Imobiliários tem sede em Brasília e atua nos mercados do Rio de Janeiro e Natal. Sobre a Hima Participaçóes sA não foi possível obter maiores informaçóes.

11 Tal valorização se situa próxima da evolução, nesse mesmo período, do IGP-M $(42,80 \%)$, porém bem inferior à valorização do Bairro do Recife (132\%). 
Convém ressaltar que o estudo sobre o mercado imobiliário no CHR selecionou, dos 11.498 endereços existentes, ${ }^{12}$ uma amostra estatística de 307 a serem pesquisados. Desses, 168 endereços (ou seja, 49,85\% do total) haviam sido alugados ou vendidos, no período de 2008-2013. Dos 168, 60,12\% (101 endereços) correspondiam a aluguel comercial e de serviços e 31,55\% (53 endereços), a aluguel de moradias. As operaçóes de compra e venda durante os seis anos considerados representaram apenas $6,84 \%$ (12 endereços). Tais dados assinalam a significativa primazia do mercado imobiliário de aluguel, no CHR. Essa forte dinâmica de aluguel, especificamente de imóveis comerciais e de serviços, com certeza foi estimulada pelas empresas de TIC e de ensino superior, bem como pelo estímulo ao consumo.

Afinal, na primeira década do presente século, ocorreu um enorme incentivo ao consumo. Como bem afirma a economista Tânia Bacelar (2014), a melhoria do quadro fiscal do Brasil abriu espaço para a retomada de políticas públicas, em especial das federais, destacando-se as políticas sociais, estimuladoras do crescimento da renda das famílias, aliado à significativa elevação do salário mínimo, em um contexto de inflação mais controlada. Segundo essa economista, "a elevação da renda das famílias e a retomada do crescimento da economia -esta associada a uma política de crédito ativa- que se acompanhou do aumento dos empregos, estimularam o consumo interno" (Ibid., p. 544). Uma das implicaçóes desse processo foi o aumento significativo da demanda por produtos do comércio varejista popular, em todas as cidades brasileiras. No caso do $\mathrm{CHR}$, representou uma dinâmica maior desse tipo de comércio, notadamente no Bairro de São José, inclusive estimulando o surgimento do comércio de produtos chineses de baixa qualidade e acirrando ainda mais a disputa entre o uso comercial e o uso habitacional ainda existente, nesse bairro e no da Boa Vista.

Esses dois bairros -com partes expressivas deterioradas- conheceram incremento dos domicílios permanentes (cerca de 13,03\%), no período de 2000 a 2010 , segundo dados do IBGE. Na maioria das vezes, os incrementos foram viabilizados pela subdivisão de algumas unidades habitacionais. Ademais, o mercado imobiliário habitacional de aluguel, nesses dois bairros, ocupa um lugar privilegiado, representando cerca de $45 \%$ dos seus domicílios particulares permanentes, mais de duas vezes o índice da Cidade do Recife, no seu todo (22,24\%). Trata-se de uma forma de acesso à moradia, empregada, sobretudo, por uma populaçáo de baixos rendimentos, insuficientes para recuperá-la e mantê-la. Assim, partes importantes das suas respectivas espacialidades são reproduzidas, sem se desprenderem das próprias heranças históricas, forjadas nos últimos 40 anos, o que se traduz na baixa valorização imobiliária.

Nos Bairros de São José e da Boa Vista, ocorreu uma valorização imobiliária, embora não no mesmo molde do Bairro do Recife: seus imóveis comerciais e de serviços valorizaram-se em 58,88\% e 41,33\%, respectivamente (Lacerda \& Anjos, 2014) no período de 2008 a 2013. Deveu-se isso à ausência de uma política de incentivo à moradia (a exemplo de locação social) e também de investimentos (na recuperação de infraestruturas urbanas). É notória, portanto, a importância do

12 Consoante o Cadastro Nacional de Endereços para Fins Estatísticos (IBGE, 2010). 
mercado de locação, tanto no que se refere a espaços construídos e destinados tanto às atividades de comércio e de serviço, quanto à habitação.

Ressalte-se, ainda, que os bairros do entorno do CHR vêm, a partir dos anos 2010, despertando o interesse do setor imobiliário de unidades habitacionais novas. Afinal, os investimentos realizados, nos últimos 25 anos, no CHR, repercutiram na geração de novos postos de trabalho e, por extensão, contribuíram para a formação de uma demanda por moradia que -em tempos de imobilidade urbana- esteja preferivelmente próxima ao trabalho. Esses bairros vêm, assim, conformando uma nova fronteira de expansão do setor imobiliário formal. Bernardino e Lacerda (2015) mostram a tensão estabelecida entre a obsolescência das moradias no cHR e a emergência de novas habitaçóes no seu entorno.

Muitos outros centros históricos brasileiros estão passando por esse mesmo processo, guardando suas especificidades, em termos de intensidade e abrangência territorial. Traçar um esboço interpretativo acerca de como os diversos tipos de incentivos -ofertados pelo poder público, nos últimos 25 anos- vêm provocando ajustes entre a oferta e a demanda dos seus respectivos mercados imobiliários constitui o objetivo do item a seguir.

\section{Esboço interpretativo do mercado imobiliário em centros históricos}

Convém esclarecer, desde logo, que elucidar o funcionamento de um mercado imobiliário significa, em última instância, desvendar os mecanismos de formação dos seus preços. Acontece que não existe abordagem -seja ela marxista, neoclássica ou cepalina- que trate de preços e de funcionamento de mercado, sem considerar as relaçóes sociais. Para Marx, por exemplo, os mecanismos de preço se inserem no interior de um modelo de concorrência perfeita. Para os neoclássicos, os mecanismos de formação dos preços são diferenciados, conforme se trate de concorrência perfeita ou de monopólio. Para os cepalinos, os preços se formam, a partir de um modelo de troca desigual, baseado no monopólio comercial ou tecnológico de um país (Lacerda, 1993).

No caso do mercado imobiliário, em centros históricos, trata-se de um problema microeconômico ${ }^{13}$ que, como se verá adiante, é influenciado por variáveis macroeconômicas e, até mesmo, não econômicas, que se traduzem nos preços praticados. Como revelado, em recente publicaçáo da autora do presente texto, em parceria com Anjos (2014), o aludido mercado funciona, a partir de um modelo de concorrência monopolista, pelas razóes abaixo anotadas.

13 O mercado imobiliário em centros históricos deve ser estudado sob a ótica da microeconomia na medida em que é o ramo da ciência econômica que investiga o comportamento dos agentes, identificando como eles agem e reagem -um com os outros-, mas levando em consideração seu ambiente de negócios (micro), sem perder de vista expectativas macroeconômicas. Embora a separação entre microeconomia e macroeconomia - esta estuda os agregados como a produçấo, o consumo e a renda do conjunto da população- seja frágil, a microeconomia apresenta uma visão "microscópica" dos fenômenos econômicos, sendo a formação dos preços o centro da análise. Tal questão é essencial notadamente em centros históricos que, além de únicos, são protegidos por meio de normativas urbanísticas. 
Esse mercado caracteriza-se pela presença de vários locadores e vendedores - proprietários ora de muitos, ora de poucos metros quadrados construídos- cuja ação isolada não tem influência nos preços que, apesar do grau de inelasticidade da oferta, flutuam segundo as condiçóes da oferta e da demanda. Por seu turno, a demanda também é caracterizada pelo elevado número de agentes (empresas, investidores individuais e usuários de habitação). Estar-se-ia, portanto, diante de uma situação de concorrência perfeita? Não é o caso, porquanto outras características estão presentes nesse mercado. De fato, o mercado competitivo pressupóe agentes munidos de informação perfeita sobre ele, e com livre acesso, além da homogeneidade das mercadorias.

Quanto ao grau de informação, vendedores e locadores dispóem de dados sobre os preços históricos dos bens imobiliários transacionados e localizados nas proximidades dos seus respectivos imóveis. Tais informaçóes, na vida moderna, podem ser obtidas por meio de sites específicos (internet) e bastam para que os imóveis não sejam vendidos ou alugados a um preço inferior àquele que vinha sendo praticado, no mercado, por produtos semelhantes. Os vendedores e locadores negociarão, se os preços forem suficientes para garantir um rendimento que gere um retorno próximo ou superior à taxa normal de juros. Da mesma forma, os compradores e os inquilinos levarão em conta os preços de unidades semelhantes já negociadas, de forma a balizar as transaçóes.

Todavia, pode acontecer -como ocorreu no início do processo de intervenção nos Bairros do Recife e de Santo Antônio- que os proprietários dos imóveis não detenham as informaçóes sobre o potencial de valorização imobiliária, diferentemente da demanda formada por empresas e por investidores individuais. Tal situação contribui para a realização de baixos preços (rent gap), assinalando uma característica de monopólio informacional por parte desses últimos agentes. ${ }^{14}$

Por outra parte, embora haja relativamente pouca elasticidade por parte da oferta, dado tratar-se de uma área institucionalmente protegida, a entrada ou a saída dos agentes desse mercado é livre, não alterando os preços. Essa característica sinaliza uma situação de concorrência perfeita.

Contudo, os bens não são homogêneos. Pelo contrário, são, como evidenciado, fortemente heterogêneos, uma vez que produzidos em épocas diferentes, em condiçôes de produção e de circulação diferentes e situados em diversas áreas (qualitativamente diferenciadas), no interior de cada um dos centros históricos. Essa última característica autoriza a falar-se de monopólio, no caso, locacional, praticado pelos proprietários dos imóveis.

Em 1933, Edward Chamberlain, no seu trabalho A Teoria da concorrência monopolista, foi um dos primeiros economistas a lançar a hipótese da concorrência monopolista. Ele adotou como centro da sua análise o mercado de compra e venda. Um dos pontos fundamentais do modelo de concorrência monopolística reside nas condiçóes da demanda. Para ele, a diferenciaçáo dos produtos induz os consumidores

14 Cabe anotar que, algumas vezes, os proprietários dos imóveis delegam a responsabilidade da transação a uma corretora imobiliária. Este agente intermediário detém, evidentemente, informaçōes sistematizadas sobre os preços históricos realizados. 
a escolherem o de um determinado vendedor, o que confere à oferta a capacidade de exercer certo controle sobre os preços. Daí que diferentes vendedores ou locadores obterão preços diversos, segundo o julgamento dos consumidores, em relação às qualidades comparativas dos produtos diferenciados, notadamente no que toca à localização.

Não significa isso que os imóveis colocados à venda ou para alugar incorporem sempre elementos monopolísticos e que, inevitavelmente, a taxa de satisfação seja mais importante que a média, o que levaria à conclusão de que os locadores e os vendedores de imóveis têm uma taxa de rendimentos acima da média. Na realidade, o que acontece é que, em certas localidades dos centros históricos, os preços de aluguel ou de compra e venda comportam elementos de monopólio e em outras, não. Nestas últimas, os locadores e os vendedores entram em concorrência.

Isso posto, passa-se a apresentar o anunciado esboço interpretativo. Destaque-se que o modelo proposto se refere aos determinantes da formação do preço do metro quadrado de venda ou aluguel nos centros históricos. Está elaborado em nível genérico, embora suficiente para considerar a influência da inovação e das variáveis de feiçôes mais simbólicas que materiais, nos preços de mercado. Por inovação, entenda-se a adequação dos imóveis (antigos) às necessidades ditadas pelas atividades contemporâneas. Daí sugerir-se o termo conservaçáo inovadora. Trata-se, portanto, da combinação de elementos antigos - referentes aos predicados arquitetônicos dos bens imóveis patrimoniais a serem conservados por força da normativa urbanísticacom elementos novos, a exemplo de dotação de refrigeraçáo, acústica, divisórios internas etc, resultando na recriaçáo de espacialidades existentes.

Conforme a figura 2, a mais importante variável endógena é o preço do metro quadrado do imóvel, resultante da articulação entre a oferta e a demanda. As variáveis exógenas mais importantes referem-se às políticas públicas nos níveis nacional, estadual e municipal (ou local). Embora tais políticas variem, de acordo com a conjuntura política e econômica, elas promovem ajustamentos entre a oferta e a demanda de imóveis. As políticas setoriais nacionais caracterizam-se por dois níveis de determinação: (i) a disponibilidade financeira e (ii) as condiçôes de crédito. $\mathrm{O}$ primeiro influencia no poder de compra da demanda (firmas, investidores individuais ou usuários de unidades habitacionais). O segundo fixa os custos financeiros que irão incidir sobre as operaçôes de crédito realizadas, o que estimulará -mais ou menos- a demanda. Essas duas instâncias de determinação estão estreitamente subordinadas à política macroeconômica, que define a política monetária -responsável pelas taxas de juros dos créditos conferidos às atividades-alvo-e institui os balizamentos gerais das demais políticas de âmbito nacional, com repercussóes nos níveis da demanda e da oferta. Citam-se como exemplos de políticas públicas setoriais de caráter nacional a Lei da Informática e o IES.

As políticas estaduais e municipais, por sua vez, podem caracterizar-se por três níveis de determinação: (i) dotação e/ou renovação de infraestruturas e serviços urbanos; (ii) renúncia fiscal; e (iii) cessão e/ou arrendamento de terrenos e espaços construídos. Tudo isso vem acontecendo, segundo já se registrou, no Bairro do Recife. Tais políticas influenciam, simultaneamente, a oferta (ao valorizar os 
imóveis, em decorrência das melhorias urbanas provocadas) e a demanda (à conta das mencionadas renúncias, cessóes e arrendamentos).

Assim, o conjunto dessas políticas setoriais -nacionais e locais- influencia o poder de compra das empresas comerciais e de serviços (dos empreendedores shumpterianos), permitindo-lhes adquirir ou alugar bens imobiliários, com infraestruturas e serviços adequados, ofertados pelas administraçóes públicas. Tais bens, mediante inovação (processos criativos), serão adaptados pelos empreendedores, para o atendimento das novas necessidades ou funçôes (TIC, lazer...). Destarte, essas políticas viabilizam "uma outra utilização de bens existentes" (Schumpeter, 2012, p. 217). Com isso, abre-se uma nova procura por bens imobiliários, pressionando a oferta. Inicialmente, como já indicado, os preços tendem a ser relativamente baixos, pelo fato de tratar-se, em geral, de edificaçôes deterioradas.

\section{FIGURA 2 Modelo interpretativo do mercado imobiliário em centros históricos}

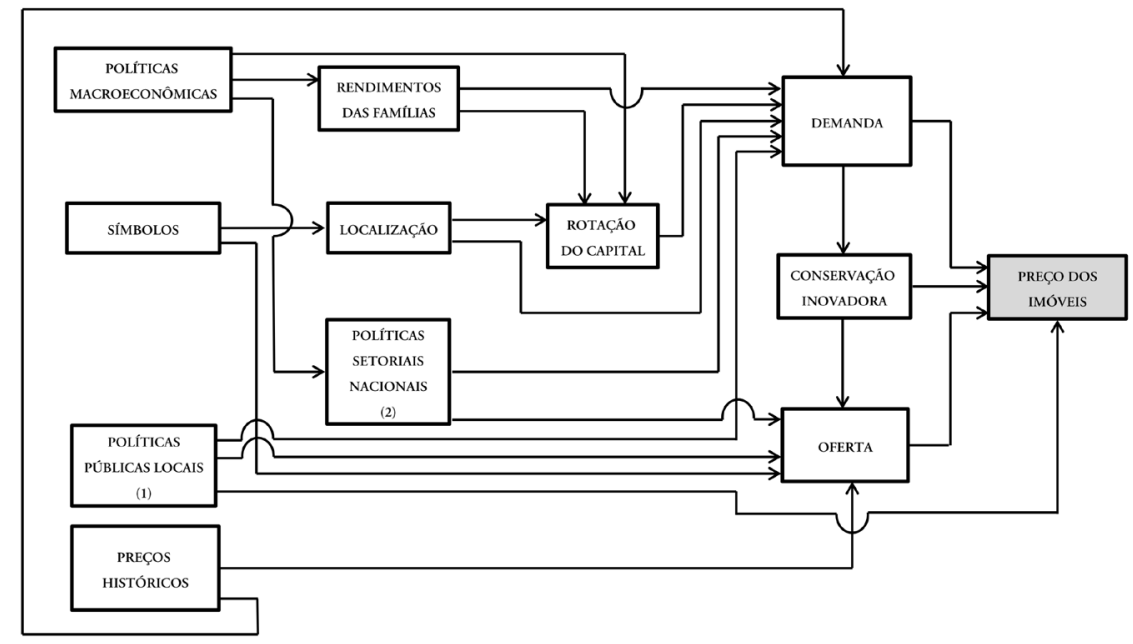

FONTE ELABORAÇÃO PRÓPRIA, 2016

DOTAÇÃO/RENOVAÇÃO DE INFRAESTRUTURA; RENÚNCIA FISCAL; CESSÃO DE ESPAÇOS CONSTRUÍDOS E TERRENOS. DISPONIBILIDADE FINANCEIRA; CONDIÇŌES DE CRÉDITO.

Entretanto, além desses empreendedores que compram ou alugam, existem investidores individuais (pessoas físicas) que, ao perceberem o potencial de valorização imobiliária, adquirem imóveis, visando à apropriação de ganhos imobiliários, mediante o aluguel. $\mathrm{Na}$ ausência de crédito direcionado a esses investidores, eles, na maioria das vezes, relegam aos empreendedores a iniciativa de recuperaçáo ou adaptaçáo dos imóveis. Esse tipo de agente é representativo, pelo menos no caso do Bairro do Recife, onde a metade do conjunto de 45 imóveis transacionados, no período de 2008 a 2013, foi adquirida por pessoas físicas. ${ }^{15}$ Cabe, porém, anotar o

15 Consoante Thomas Piketty (2014), a partir dos finais do século xx, o décimo superior da estrutura social mundial voltou a crescer e, mais ainda, o centésimo superior. Todavia, o que interessa aqui são os $9 \%$ do décimo superior, onde prevalecem as rendas do trabalho. Segundo esse economista, 
posicionamento duplo desse tipo de agente: por um lado, compóem a demanda por imóveis e, por outro, atuam na oferta, como locadores.

O crescimento da demanda de imóveis - por firmas e pessoas físicas-, em relação a uma oferta de pouca elasticidade, favorece a formação de preços de monopólio locacional. A atuação desses agentes privados -em determinadas áreas de um centro histórico- incentivada por agentes públicos, tem como resultado a recriação da espacialidade ali existente.

Acresce, ainda, a demanda representada por futuros usuários de habitaçóes localizadas nessas áreas. Como, em geral, se trata de populaçôes de baixa e média renda, políticas para a recuperação dos espaços públicos e das habitaçóes, com certeza repercutiriam em termos de maior pressão sobre a demanda por habitação nessas áreas, inclusive à conta dos empregos que ali estariam sendo gerados. $\mathrm{Na}$ ausência delas, assiste-se à realização de baixos preços imobiliários e, por extensão, à reprodução da espacialidade ali existente, o que vem acontecendo em localidades situadas nos Bairros de São José e da Boa Vista.

É também necessário levar-se em conta o preço histórico, resultado do funcionamento do modelo de interpretaçáo aqui apresentado. Entretanto, para que os imóveis se realizem, de fato, no mercado, é imperativo que seus proprietários levem em consideração o nível de solvabilidade da demanda, formada pelas firmas e pelos investidores individuais, bem como pelos usuários das habitaçôes. Para as empresas e investidores individuais, importa a rotação do capital (o volume de negócios), proporcionada pela localização e pelos símbolos (as representaçôes espaciais) a ela relacionados. A rotação do capital é influenciada pelas políticas macroeconômicas, que definem, entre outras coisas, o nível dos rendimentos familiares. Esses rendimentos podem incentivar o consumo das famílias, favorecendo, por exemplo, o comércio varejista nas áreas centrais -caso do Bairro de São José- e, por extensão, influenciando na demanda por espaços comerciais e de serviços.

Convém registrar que a pesquisa detectou a importância dos símbolos na conformação dos preços imobiliários, nos centros históricos. Essa importância exprime-se numa forte demanda por certas localidades -como no caso do Bairro do Recife- às quais confere uma função de diferenciação (prestígio, grife), reforçando a renda de monopólio locacional, nos termos anteriormente referidos.

Enfim, como os centros históricos, em geral, são formados por diversos submercados imobiliários, existe uma diferenciação de preços. Estar-se-ia, pois, diante de um mercado, cujos preços, muitas vezes, oscilam de um nível muito baixo, a exemplo do Bairro de São José (onde eles acompanham o poder de compra de empresas do comércio varejista de produtos populares e de uma população de mais baixa renda) a um nível muito alto, como é o caso dos imóveis situados no Bairro do Recife. Esses preços informam sobre dois movimentos simultâneos: (i) o de reprodução das espacialidades existentes, caracterizadas pelo estado precário de conservação dos

isso nâo quer dizer que as rendas do capital, a exemplo de rendas imobiliárias, nấo estejam aí presentes. É comum nessa faixa que, à renda relativa ao salário, sejam adicionadas as provenientes de aplicações financeiras e/ou de aluguéis. Apenas uma parte do salário vira consumo. Como não gastam tudo o que ganham, investem o que poupam em açóes, em imóveis, formando uma classe média patrimonial. 
imóveis e dos espaços públicos; e (ii) o de recriação de outras, por meio das açóes dos agentes privados, impulsionados pelas.

\section{Agradecimentos}

Este artigo conta com o apoio financeiro do Conselho Nacional de Desenvolvimento Científico e Tecnológico $(\mathrm{CNPq})$ e da Fundação de Amparo à Ciência e Tecnologia de Pernambuco (Facepe).

\section{Conclusáo}

O mercado imobiliário formal -quer seja de unidades habitacionais novas, quer seja de imóveis situados nos centros históricos- é regido por uma norma geral (ou universal): funciona segundo um modelo de concorrência monopolista. É a partir desse modelo que seus agentes centrais -vendedores, compradores, locadores e inquilinos- tomam suas decisóes. Ademais, dependendo da sua dimensão territorial e das suas funcionalidades, pode conformar um único mercado ou compreender diversos submercados.

Todavia, esses dois tipos de mercado formal guardam particularidades. De fato, enquanto no mercado de unidades novas, a oferta -comandada pelos promotores imobiliários- é generosamente elástica, nos centros históricos a oferta é praticamente inelástica, uma vez que regida por normas protecionistas. No primeiro caso, a destruição criativa permite a criação de novos produtos e novas espacialidades. No segundo, as espacialidades devem ser reinventadas ou recriadas. O velho deve modernizar-se, para abrigar o novo; a destruição é institucionalmente interditada. Daí sugerir-se, como já anotado, a expressão conservação inovadora. ${ }^{16}$

Tanto em um caso, como no outro, as novas combinaçôes só se realizam, mediante a intervenção estatal por meio de políticas públicas de crédito e de incentivo, a exemplo da dotação e/ou renovação de infraestrutura, renúncia fiscal e cessão de terrenos e espaços públicos construídos. São essas políticas que, em tempos de globalização, viabilizam o retorno do interesse do capital pelos centros históricos e, por desdobramento, os ajustes entre a oferta e a demanda dos imóveis neles localizados. Sua presença recria espacialidades existentes. Sua ausência reproduz outras. Significa isso que, no caso dos centros históricos brasileiros, o mercado -por si mesmo- não dá conta de promover sua recuperação.

Quanto ao modelo interpretativo do mercado imobiliário, nessas áreas, o esboço apresentado mostra uma desvinculação do preço de mercado dos bens imobiliários, em relação às suas condiçôes originais de produção). Diferentemente do mercado imobiliário de unidades habitacionais novas, o dos centros históricos quase não se apoia na produção de novos imóveis. Os promotores imobiliários tradicionais pouco

16 As cidades europeias são, nesse sentido, exemplares. Conseguiram preservar parte importante do seu patrimônio histórico e cultural, mediante sua adequação às exigências das atividades modernas. 
atuam. Quando atuam, devem seguir rígidos parâmetros urbanísticos. Nos últimos 25 anos, é o poder de compra da demanda -formada notadamente por firmas (comércio e serviços) e por investidores individuais (pessoas físicas) e, portanto, por sujeitos econômicos, impulsionados pelo poder público- que vem determinando os preços praticados no mercado em questão. Dito de outra maneira, são as açóes governamentais que vêm proporcionando a circulação dos bens imobiliários nos centros históricos e, por extensão, sua valorização, em determinadas porçóes de tais centros, nas cidades brasileiras.

\section{Referência bibliográficas}

Albuquerque, I. J. C. de (2016). A utilização das normas indutoras como instrumento jurídico de revitalização de zona histórica: o caso da implantação do Porto Digital no Bairro do Recife. Dissertação de Mestrado, Programa de Pós-graduação em Desenvolvimento Urbano/ Universidade Federal de Pernambuco, Recife.

Brasil. Lei n ${ }^{\circ}$ 8248/1991. Dispóe sobre a capacitação e competitividade do setor de informática e automação, e dá outras providências. Em https://presrepublica.jusbrasil.com.br/ legislacao/104161/lei-8248-91. Acesso: 13 de março de 2015.

Araújo, T. B. (2014). Nordeste: desenvolvimento recente e perspectivas. In: P. F. de Guimarães, R. A de Aguiar, H. M. M. Lastres \& M. M. de Silva (Orgs.), Um olhar territorial para o desenvolvimento (pp. 541-560). Rio de Janeiro: Banco Nacional de Desenvolvimento Econômico e Social (BNDES).

Bernardino, I. L. \& Lacerda, N. (2015). Centros históricos brasileiros: tensóes entre a obsolescência imobiliária e a construção de novas espacialidades. Revista Brasileira de Estudos Urbanos e Regionais, 17(1), 61-74. Em http://www.anpur.org.br/publicacao/ arquivos/20160517100357Volume_17_-_numero_1.pdf

Chamberlain, E. (1953). La théorie de la concurrance monopoliste. Paris: Presses Universitaires de France,

Jornal do Commercio. Nova expansão do Porto Digital. Recife, 09.10.2015.

Lacerda, N. (1993). La production sociale des intérêts fonciers et immobiliers: Le cas de Recife (Brésil). Tese de doutorado., Université de la Sorbonne Nouvelle, Paris.

Lacerda, N. \& Anjos, K. A. (2014). Regulação da dinâmica espacial nos centros históricos brasileiros em tempos de globalização: o caso do Recife (Brasil). In A. C., Fernandes, N. Lacerda \& V. Pontual (Orgs,), Desenvolvimento, planejamento e governança: o debate contemporâneo em 30 anos de ANPUR (pp. 455-482). Rio de Janeiro: Letra Capital / Associação Nacional de Pós-graduação e Pesquisa em Planejamento Urbano e Regional. (Anpur).

Lacerda, N., Zancheti, S. \& Diniz, F. (2000). Planejamento metropolitano: uma proposta de conservação urbana e territorial. EURE, 26(79), 77-89. http://dx.doi.org/10.4067/ S0250-71612000007900005

Lacerda, N. \& Fernandes, A. C. (2015). Parque tecnológico: entre a inovação e renda imobiliária no contexto da cidade do Recife. Cadernos Metrópole. 17(34), 329-354. Em http:// www.scielo.br/pdf/cm/v17n34/2236-9996-cm-17-34-0329.pdf 
Nakagawa, F. (2014). Valorização de imóvel no Brasil foi a maior do mundo nos últimos 5 anos. Estadão. Economia \& Negócios, 17 jan. 2014. Em http://economia.estadao.com.br/ noticias/geral,ministro-indica-que-pode-negociar-usinas-da-cemig,70001938008

Piketty, T. (2014). O capital no século XXI. Rio de Janeiro: Intrínseca.

Recife. Lei no 17.244, 27 de julho de 2006. Institui o programa de incentivo ao Porto Digital. Em http://www.legiscidade.recife.pe.gov.br/lei/17244/

Recife. Lei no 17.942, de 27 de 3 de dezembro de 2013. Altera a lei municipal no 17.244 de 27 de julho de 2006. Em http://www.legiscidade.recife.pe.gov.br/lei/17942/

Recife. Lei $\mathrm{n}^{\circ}$ 18.168, de 29 de outubro de 2015. Altera o dispositivo da Lei $\mathrm{n}^{\circ}$ 17.244, de 27 de julho de 2006. Em https://leismunicipais.com.br/a/pe/r/recife/leiordinaria/2015/1816/18168/lei-ordinaria-n-18168-2015-altera-dispositivos-da-lei-n17244-de-27-de-julho-de-2006-modificada-pela-lei-n-17-762-de-28-de-dezembrode-2011

Schumpeter, J. (2012). Teoria do desenvolvimento econômico. Uma investigação sobre lucros, capital, crédito, juro e o ciclo econômico. Lisboa: Fundação Calouste Gulbenkian.

Shimbo, L. Z. (2011). O "segmento econômico" do mercado imobiliário e os programas públicos: faces da política habitacional contemporânea no Brasil. Em S.; Leal \& N. Lacerda (orgs.), Novos padröes de acumulação urbana na produção do Habitat. Olhares cruzados Brasil-França (pp. 123-149. Recife: Editora Universitária UfPE.

Smith, N. (2003). La gentrification généralisée: d'une anomalie local à la "régénération" urbaine comme stratégie urbaine globale. Em C. Bidou-Zachariasen (ed.), Retours en Ville (pp. 45-72) Paris: Descartes \& Cie. 